\title{
Developmental Psychology, Child
}

National Cancer Institute

\section{Source}

National Cancer Institute. Developmental Psychology, Child. NCI Thesaurus. Code C16426.

Developmental psychology research focusing on the childhood years. 